\title{
Ethics in emergency care: nursing attitudes
}

Slavica Klancar, RN, Emergency Department of Internal Medicine, University Medical Centre, Clinics for Surgery, University Medical Center, Ljubljana, Slovenia (E)

Melanija Plancak, RN, BSc, Emergency Department of Internal Medicine, University Medical Centre, Clinics for Surgery, University Medical Center, Ljubljana, Slovenia

Slavica Klancar, Emergency Department of Internal Medicine, University Medical Centre, Clinics for Surgery, University Medical Center, Zaloska 7, 1000 Ljubljana, Slovenia. e-mail: slavica.klancar@kclj.si

\section{INTRODUCTION}

Emergency nursing care presents many legal and ethical dilemmas which influence and shape professional working and decision-making. In the field of emergency nursing, it is very important to consider 'special circumstances' that may influence a specific situation, such as sudden illness or injury and the need to make immediate decisions about care and treatment. Although in Slovenia, the Code of Ethics for Nurses of Slovenia provides a general guide to support ethical decision-making, specific detail concerning particular situations and dilemmas would help to improve nurses' understanding.

The authors attempted to identify the common ethical

\section{Table 1. Ethical dilemmas found in emergency nursing}

\section{Dilemma or situation}

Should relatives be present during resuscitation?

Should a patient's identity be publicised in the media, such as on TV or in the newspapers

Do we (nurses) consider protection of personal data and data about patient's health?

Do we always provide a written report of report incidents?

Do we intervene at a time when the doctor is not present and exceed our competence?

Can we give information about a patient's health to relatives? Can we contact the parents of a teenager in cases of drug abuse?

Do we treat patient who have ingested too much alcohol and/or drugs with respect?

Do we sometimes ignore a patient, e.g. nurses holding a private conversation in the presence of a patient?

Are nurses always able to express empathy?

Is it ethically correct to express sympathy to the patient?

Do we respect patient's privacy when performing nursing care procedures?

Do we always treat a patient who has died in an ethical manner?

Do we warn patients about their rights?

Is it ethically correct that a doctor withholds information about an HIVor hepatitis-positive patient from a nurse?

Are we aware that the law obliges us to give first aid to any member of the public?

Can we perform medical procedures without the agreement of the patient?

Do we allow patient to see his medical documentation?

Do we document all nursing care?

\section{Majority opinion}

Perhaps, since they can also be present during birth or when a relative dies

No, unless the patient has given written consent and to further educational, scientific or professional aims

Yes

Yes, but not for every incident, and not in every centre

No. Although some said 'yes' in life-threatening situations, some life-saving procedures are allowed with a doctor's written permission

No. Although some said 'yes' in situations in which relatives were involved in care of the patient In our country, the law prohibits this after the age of 15 years

Yes. Nurses should not show contempt

No. Although sometimes mistakes can be made and this may happen

Yes. Although a few nurses stated ' $N$ o' in some situations

No. Our emotions should not show sympathy because our professional behaviour is jeopardised Yes, we try to do so

Yes. It is also written in the United Nations' declaration of human rights that the human body should be treated with all respect

Yes. Nurses have to warn patients about their rights

No. Nurses have to protect a patient's information. The law says a doctor can withhold patient information as long as the life of others is not compromised

Yes. This is according to the Code of Ethics for Nurses of Slovenia

Yes, in life-threatening situations, or when a patient is unable to make a decision in consultation with relatives

Yes. A patient has got a right to see his documentation

Not always 


\begin{tabular}{|c|c|c|c|}
\hline Question & Yes & No & Other \\
\hline 1. Is your professional activity based on decisions according to how they benefit the patient? & $123(95.4 \%)$ & $3(2.3 \%)$ & $3(2.3 \%)$ \\
\hline 2. Do you complete the necessary nursing documentation? & $88(68.2 \%)$ & $33(25.6 \%)$ & $8(6.2 \%)$ \\
\hline 3. Do you consider data protection issues and do you keep information regarding patients' health confidential? & $114(88.4 \%)$ & $9(7 \%)$ & $6(4.6 \%)$ \\
\hline 4. Do you think it is right to show a patient's identity to the public, e.g. a resuscitation on film or in a photograph? & $19(14.7 \%)$ & $105(81.4 \%)$ & $5(3.9 \%)$ \\
\hline 5. Do you talk about your personal business in the presence of patients? & $51(39.5 \%)$ & $70(54.3 \%)$ & $8(6.2 \%)$ \\
\hline $\begin{array}{l}\text { 6. Do you take care not to talk about a patient's health or condition where you might be overheard by other patients, } \\
\text { such as in a corridor? }\end{array}$ & $97(75.2 \%)$ & $27(20.9 \%)$ & $5(3.9 \%)$ \\
\hline 7. Do you respect a patient's privacy when performing medical and nursing care procedures? & $91(70.5 \%)$ & $29(22.5 \%)$ & $9(7.0 \%)$ \\
\hline 8. Do you respect a patient's right of choice and to make decisions? & $112(86.8 \%)$ & $12(9.3 \%)$ & $5(3.9 \%)$ \\
\hline $\begin{array}{l}\text { 9. Do you treat alcoholic patients, aggressive patients, drug abuse patients or displaced persons with the same } \\
\text { respect as other patients? }\end{array}$ & $67(51.9 \%)$ & $54(41.9 \%)$ & $8(6.2 \%)$ \\
\hline 10. Do you contact parents of teenagers in cases of drug abuse despite the law? & $16(12.4 \%)$ & $83(64.3 \%)$ & $30(23.3 \%)$ \\
\hline 11. Do you find it acceptable for relatives to be present during resuscitation? & $15(11.6 \%)$ & $108(83.7 \%)$ & $6(4.7 \%)$ \\
\hline 12. Do you give first aid whenever necessary? & $105(81.4 \%)$ & $17(13.2 \%)$ & $7(5.4 \%)$ \\
\hline 13. Do you exceed your competence and assist a patient when a doctor is not present? & $37(28.7 \%)$ & $85(65.9 \%)$ & $7(5.4 \%)$ \\
\hline 14. Do you undertake doctor's orders given by telephone? & $80(62 \%)$ & $38(29.5 \%)$ & $11(8.5 \%)$ \\
\hline 15. Do you think it is ethical that doctors withhold information about HIV- or hepatitis-positive patients from the nurse? & $7(5.4 \%)$ & $121(93.8 \%)$ & $1(0.8 \%)$ \\
\hline 16. Do you treat the body of a dead patient in an ethical manner? & $108(83.7 \%)$ & $12(9.3 \%)$ & $9(7.0 \%)$ \\
\hline 17. Do you report all incidents to your team manager? & $95(73.7 \%)$ & $27(20.9 \%)$ & $7(5.4 \%)$ \\
\hline 18. Do you offer 'consolation' to patient in adequate way? & $118(91.5 \%)$ & $3(2.3 \%)$ & $8(6.2 \%)$ \\
\hline 19. Do you always care for, or communicate with, the patient's relatives in an adequate way? & $109(84.5 \%)$ & $15(11.6 \%)$ & $5(3.9 \%)$ \\
\hline
\end{tabular}

dilemmas faced by emergency nurses and the responses of nurses to specific situations or dilemmas. Through this article, they hope to encourage further discussion.

\section{Research question}

Do nurses by their action and behaviour always promote the confidence of society, confirm and increase the good name of nursing as a profession and do they protect the interests of each patient?

\section{Research methods}

Questionnaires were distributed to nurses attending two conferences held in Slovenia. The level of research was informal and descriptive with the aim of raising further discussion about the dilemmas found in emergency care nursing.

\section{QUESTIONNAIRE 1}

Questionnaire 1 was presented at the International Symposium on Emergency Medicine in Portoro, in June 2000. It outlined some of the common ethical dilemmas presented in emergency care and requested potential solutions to the dilemmas presented. Individuals were asked to answer based on their own perspective of the identified situation. The questionnaire served to clarify the dilemmas that nurses working in emergency care encounted. The data were analysed in a descriptive way, without the use of statistical analysis (Table 1).

\section{QUESTIONNAIRE 2}

The study was continued at the annual seminar of the Nurses Association in Emergency Medicine of Slovenia in October 2001. One hundred and twenty nine nurses completed Questionnaire 2. The results are presented in Table 2.

\section{DISCUSSION}

Although this study can only be considered to provide preliminary results with the aim of raising discussion, it seems, as might be expected, that most emergency nurses do consider ethical dilemmas, are aware of the legal implications and take patients' rights into consideration.

Three percent of nurses chose to answer questions with 'not always' or 'it is not possible to give an overall yes or no'. This may reflect the reality of ethical decision-making as decisions are not always 'clear-cut'. The results suggest that the majority of nurses $(59.3 \%)$ work according to the Code of Ethics for Nurses of Slovenia. Three percent of the respondents chose neither 'yes' nor 'no', but answered with 'not always', 'it is not possible', 'I try to', 'if it is possible', 'usually' or 'I hope'.

The questions were phrased to elicit either positive ('yes') or negative ('no') responses; $34.7 \%$ of nurses answered 'no' to some questions. It is important to consider the context and reasons why these answers were given. Further research is required to explore this area. Some further questions include the following. What is a nurse's knowledge of the Code of Ethics for Nurses of Slovenia? What situations influence decision-making? How do nurses interpret the law?

\section{CONCLUSION}

When trying to act in the best interest of patients, nurses have a broader responsibility to find an answer that complies with a code of ethics. At the same time, nurses need to ensure that they do not violate the law. The authors hope that this article will stimulate further consideration of the base for ethical evaluation in the work of nurses with the aims of encouraging professional growth, greater job satisfaction and the provision of high-quality patient care. 